\title{
Raúl Solnado e o Teatro Villaret 1965-1974
}

\section{Ana de Carvalho'}

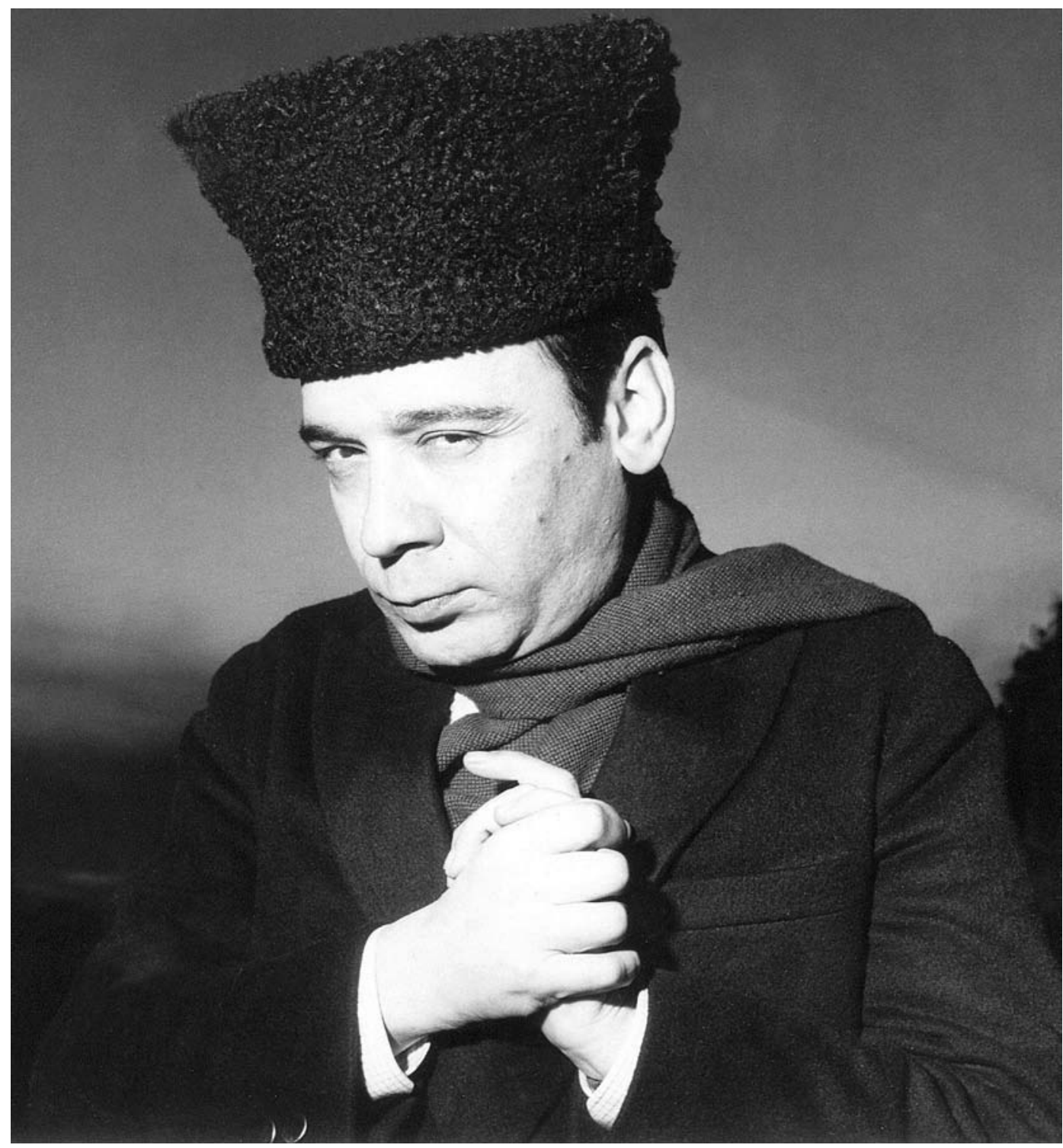

O impostor geral,

de Gogol / Francisco Mata

e Carlos Wallenstein,

enc. Francisco Ribeiro,

Teatro Villaret, 1965

(Raúl Solnado),

fot. Augusto Cabrita.

0 que de mais legítimo podemos dizer sobre Raúl Solnado é que ele se tornou parte importante da memória cultural do nosso país. Nessa edificação de memória existe um marco, ainda hoje visível, que é o Teatro João Villaret, em Lisboa.

0 Teatro Villaret, como acabaria por ficar conhecido, foi de facto o sonho, o grande projecto de Raúl Solnado. E se só por si, no meu entender, este facto mereceria que sobre ele atentássemos, não me resta a menor dúvida de que a dimensão deste projecto é suficientemente importante, determinante mesmo, para nele identificarmos uma forma de transformação cultural deste pais.

Para que se perceba melhor esta minha convicção é conveniente fazer uma breve caracterização do ambiente em que nasce e é concretizada a ideia do Teatro Villaret. Nos finais da década de 50, Solnado conhece outras realidades teatrais no estrangeiro, principalmente no Brasil. É neste pais que contacta com salas de espectáculo para Nacional do Teatro. 
cento e vinte e dois Sinais de cena 5. 2006 Arquivo Solto

pequenas plateias: os chamados teatros de bolso (little theaters), que surgiram um pouco por todo o mundo na sequência da segunda guerra mundial. É ainda no Brasil que conhece os chamados espaços mistos, edifícios onde podiam coabitar residentes e outras instituições, como salas de espectáculo. Este tipo de sala, que permitia uma maior aproximação entre o público e a cena, uma relação mais intima e, nesse sentido, uma maior interiorização e cumplicidade, agradara particularmente a Solnado, habituado às grandes plateias e a "banhos" de multidões.

Por outro lado, no início dos anos 60, Solnado estava em pleno auge da sua carreira de humorista e, graças aos famosíssimos monólogos que punham o país a rir às gargalhadas, tornara-se um dos maiores casos de popularidade de sempre. 0 sucesso, porém, tornara-se asfixiante para o próprio actor que, como referiu em entrevista ao suplemento Pública (17/02/2002), chegava a sentir-se perseguido por ele próprio! As pessoas sabiam de cor os seus monólogos, entretanto editados em disco, chegando a ser frustrante fazer espectáculos em que o público se adiantava nas deixas. Solnado mesmo sem ser em cena, tinha que corresponder, permanentemente, à imagem que criara. Este sucesso esmagador terá contribuído bastante para o desejo de novas experiências na arte da representação. É preciso lembrar que a oferta de espectáculos de teatro era então, em número e em qualidade, bastante limitada. Por um lado, não nos podemos gabar de ser um país com forte tradição na produção teatral, por outro, a censura era um condicionamento a ter em devida conta e, por outro ainda, o funcionamento

No registo áudio do programa Zip-Zip, Solnado, conta, em entrevista na última sessão, as peripécias por que passou para construi

o teatro: "Ouvi coisas terriveis dos construtores civis. Houve um até que me disse: 'Um teatro?! Eu não gosto de bailaricos cá no prédio!" das companhias de teatro em Portugal (leia-se Lisboa e Porto) estava dependente da figura do todo poderoso empresário que geria toda a máquina teatral e, nesse sentido, também a escolha de elenco e de repertório.

É neste cenário que Raúl Solnado decide avançar para a concretização do seu sonho: a construção de um teatro de pequenas dimensões, onde ninguém Ihe dissesse o que tinha de fazer e onde pudesse realizar-se como actor experimentando novos repertórios, criando o seu próprio modelo.

Depois de alguns anos em demanda de um espaço (pois não era fácil construir um edifício de raiz no centro da cidade...), Solnado descobriu um prédio em construção na Av. Fontes Pereira de Melo cujo empreiteiro era conhecido do seu pai. Esta pequena coincidência pode ter sido responsável pela existência do Teatro Villaret, já que todas as tentativas até então tinham resvalado ao primeiro contacto com o construtor'. Assim, em 1963, Solnado e Rui Martins, cenógrafo com quem veio a fazer sociedade, alugam por 25 contos o rés-do-chão e a cave do referido prédio em construção, constituem uma sociedade (TEBO - Teatro de Bolso, Lda.) e no Dia Mundial do Teatro (27 de Março), por sinal a primeira vez que tal data era comemorada em Portugal, o actor anunciou em conferência de imprensa a construção do seu Teatro de Bolso, em plenas avenidas novas, nessa altura uma zona em expansão da cidade de Lisboa, de fácil acesso e seguro estacionamento.

Solnado contava com a vantagem de ser quem era, com o Decreto-Lei 42660 (de 20/11/59) - que passou a permitir a construção de salas de espectáculo em espaços mistos -, e com amigos bem colocados que se disponibilizaram enquanto fiadores do empréstimo bancário que contraiu. Conseguida a autorização para a escavação de $2 \mathrm{~m}$ abaixo do nivel do solo, as obras começaram em 1964.

Também ao nível da construção o novo Teatro representava de facto uma nova maneira de encarar e de fazer esta arte e não apenas pelas suas pequenas dimensões. De facto, o Teatro Villaret foi pensado por um actor que conhece as necessidades da cena e dos que nela trabalham e que tudo fez para ir ao encontro do que considerava uma exigência dessa actividade. Inovou na organização da plateia: sem a tradicional divisão de lugares, com cadeiras desencontradas, em plano inclinado, garantindo boa visibilidade e uma perfeita acústica em qualquer ponto da sala; inovou no equipamento técnico, topo de gama (188 projectores, tecto móvel, órgão de luz e saídas de som estrategicamente localizadas); inovou no acolhimento e conforto do espectador (climatização geral, fácil acesso às bilheteiras, ao foyer e à sala); inovou também na comodidade e necessidades do actor (sala de ensaios com dimensões iguais às do palco, ar condicionado nos bastidores e camarins - com água quente e fria - 


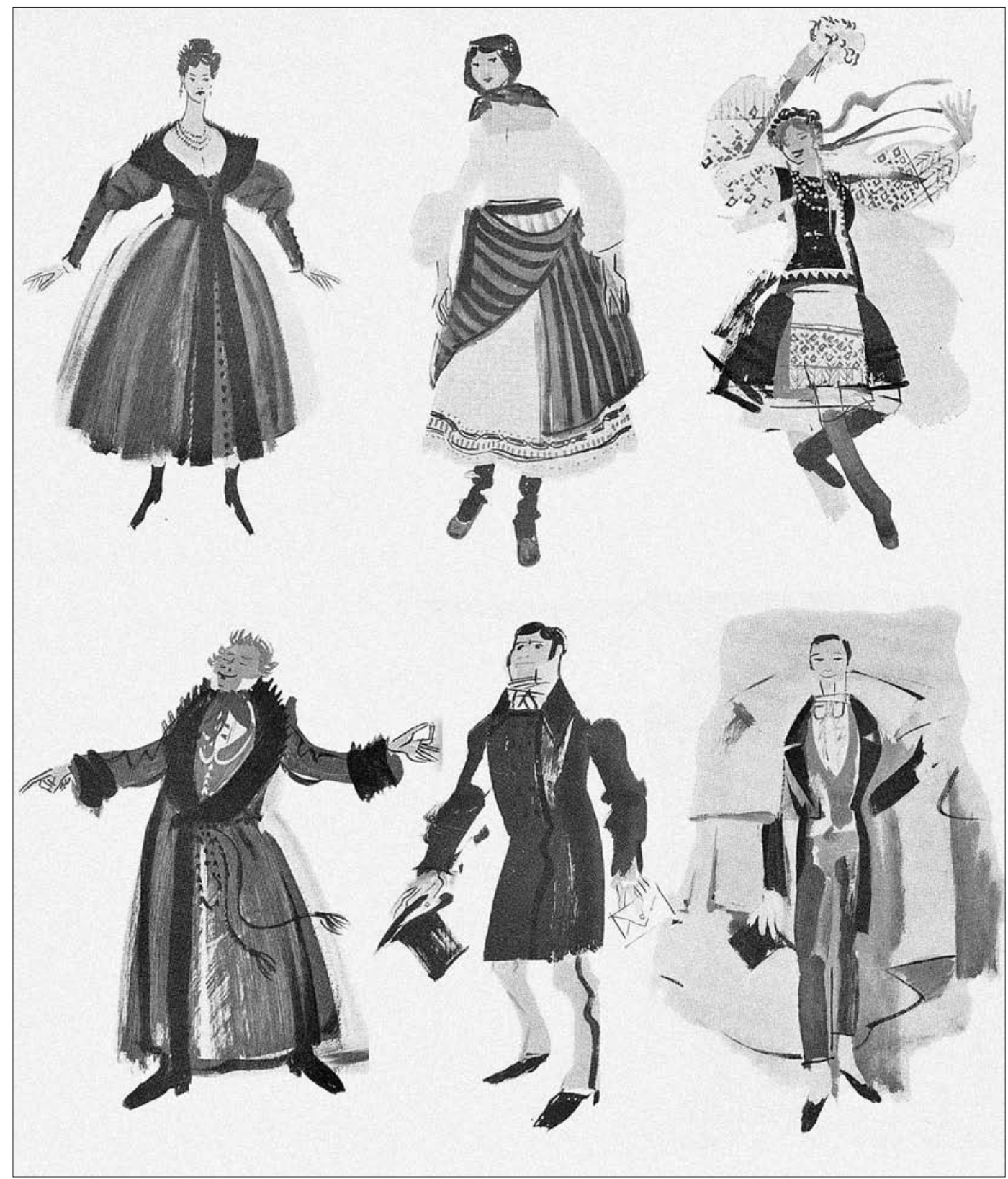

Figurinos de Daciano da Costa para 0 impostor geral, de Gogol I Francisco Mata e Carlos Wallenstein, enc. Francisco Ribeiro, Teatro Villaret, 1965 [programa do espectáculo].

rede de intercomunicadores...) e inovou também na forma como se apresentou, ou seja, no décor. Neste aspecto é relevante a colaboração de Daciano da Costa, o responsável pela decoração do novo teatro, a quem Solnado, após uma visita à Aula Magna (da Reitoria da Universidade de Lisboa), pediu que fizesse o seu teatro impondo-Ihe apenas a condição de este ser azul e vermelho. As (muitas) limitações e dificuldades que a construção do edifício apresentava foram verdadeiros desafios à criatividade. Daciano da Costa soube transformar os problemas em vantagens e toda a organização do espaço e decoração interior não eram apenas uma questão de gosto, mas antes correspondiam a um harmonioso e inventivo diálogo entre três dimensões: a estética, o conforto e a funcionalidade.

A 10 de Janeiro de 1965, o Teatro Villaret abria oficialmente as portas da sua carreira com a comédia musical 0 impostor geral, uma adaptação de Francisco Mata e Carlos Wallenstein de O inspector geral, de Gogol, com encenação de Francisco Ribeiro, direcção musical de
Jorge Costa Pinto, montagem e cenografia de Rui e Hernâni Martins, figurinos e maquetas de Daciano da Costa. Há 14 anos que não se construía um teatro em Lisboa e, pela primeira vez em Portugal, um actor construía o seu próprio teatro. A estreia/inauguração foi um acontecimento nacional ao qual estiveram presentes individualidades das mais diversas áreas. Solnado, porém, não esqueceu a classe artística que, "pela actividade concorrencial", não poderia comparecer e, por isso, decidiu que a ante-estreia começaria às $2 \mathrm{~h}$ da manhã, de forma a permitir que todos os colegas e demais trabalhadores de outros teatros pudessem estar presentes. Nessa madrugada os 426 lugares não chegaram! E não esqueceu também os anónimos que ajudaram a construir o seu sonho, que "transportaram as pedras". Foi a esses que dedicou o primeiro texto que aparece no programa da estreia:

\section{A picareta de oiro...}

Foi conferida ao Manel. Desde o dia em que começaram as obras do teatro ele não desistiu. Cavou, raspou, estucou, 


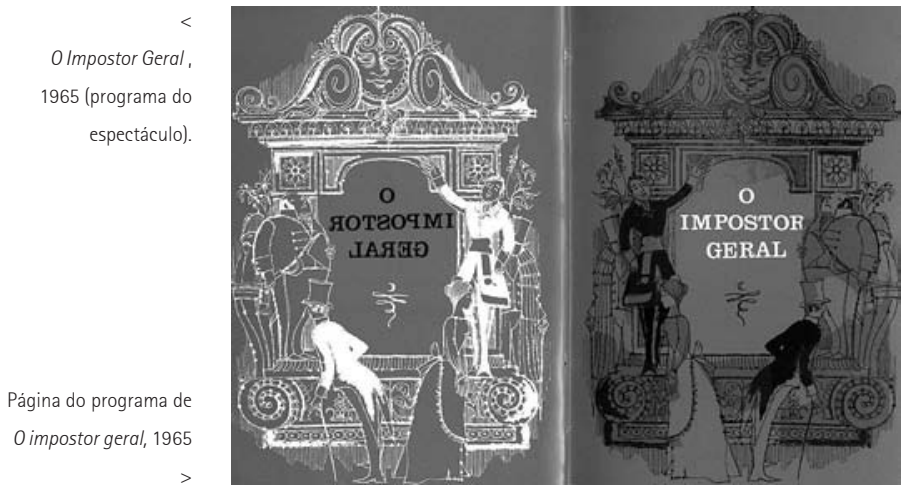

0 impostor geral

de Gogol / Francisco Mata e Carlos Wallenstein, enc. Francisco Ribeiro,

Teatro Villaret, 1965 (elenco completo)

[programa do espectáculo].

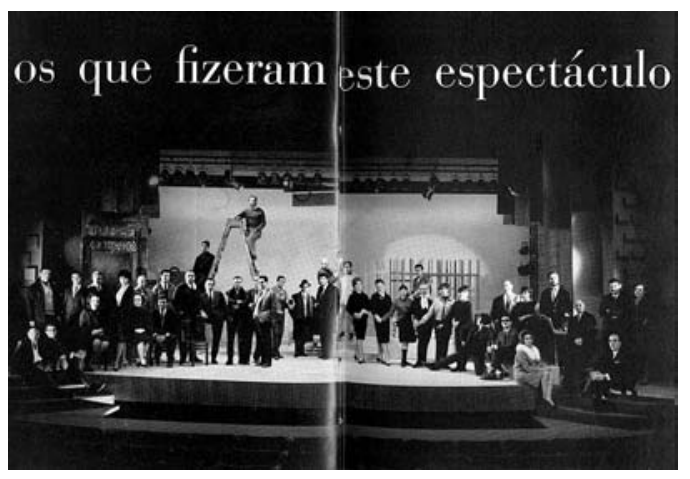

Programa de

Assassinos associados,

de Robert Thomas,

enc. João Bethencourt, Teatro Villaret, 1967.

pintou e arrumou. 0 Manel não presta para barómetro. Sua no Verão e sua no Inverno. Às cinco horas, quando o mestre dava o sinal para parar o trabalho, o Manel estava embalado e só parava lá para as cinco e dez, cinco e um quarto.

Parava e sorria. Olhava desvanecido para os tijolos e para as tábuas e dava um jeitinho na pá para que ficasse direita. Metia a fralda da camisa para dentro, subia as escadas lentamente, com aquele ar de quem ganha honradamente o seu dinheiro. E durante mais de um ano, das oito da manhã às cinco da tarde, o Manel ajudou a construir um teatro. Talvez nem lhe passe pela cabeça o que isso significa. Mais: talvez desconheça que há Teatro. Mas juro que quando pela primeira vez o pano subir e os projectores se acenderem juro que hei-de pensar fraternalmente no Manel.

Quanto ao espectáculo, os críticos maioritariamente aplaudiram e elogiaram, mas encontramos também críticas menos favoráveis, com particular destaque para os aspectos da técnica, cenário e música. Opto por transcrever a opinião de Urbano Tavares Rodrigues que, com alguma isenção, parece fazer a síntese de todas as críticas:

${ }^{2}$ Programa de 0 impostor geral, 1965

Jornal de letras e artes, $17 / 10 / 65$.

${ }^{4}$ Durante o periodo em

que esteve ligado ao Teatro Villaret, Solnado fez duas revistas fora do Villaret: Pois, pois..., em

1968, no Teatro Variedades e P'rá frente

Lisboa!, em 1972, no Teatro Monumental.
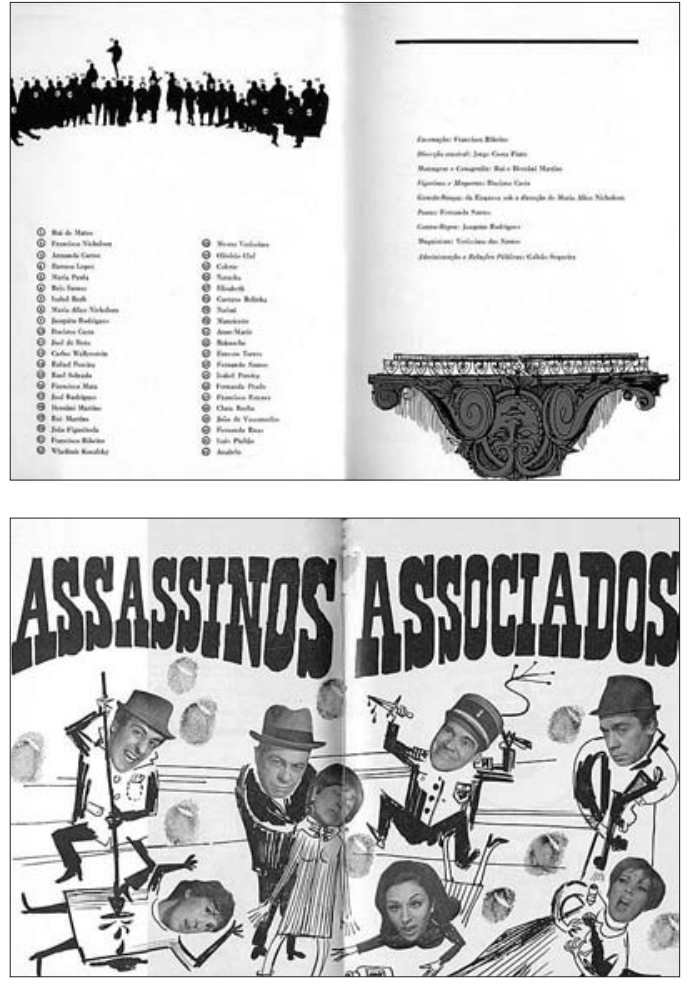

enxertando anacronismos e paralelos jocosos no contexto de uma crítica social que, por ser divertida, não é, na origem, menos acerada e demolidora. E disso mesmo, afinal, apesar de tudo, alguma coisa, em boa hora sobejou.

Se relativamente ao espaço o Teatro Villaret se revelou inovador, o mesmo se pode dizer quanto ao funcionamento, à programação e à imagem. Havia, de facto, um forte espirito de equipa neste teatro: estar ligado ao Villaret, desempenhando funções de actor ou outras, era "vestir a camisola", pertencer àquele "clube". 0 "projecto Teatro Villaret" não era exclusivamente de Raúl Solnado, mas um pouco de todos os que nele trabalhavam. Claro que a pessoa de Solnado não era indiferente a este espírito de corpo: ele era um bom gestor de relações humanas e um factor de agregação fundamental. Por isso um dia, após um periodo de ausência em que estava a fazer revista no Parque Mayer, os colegas e demais trabalhadores esperaram pelo final da última sessão da carreira do Pois, pois... e "raptaram-no" num autocarro "desviado" para o efeito, fazendo-o entrar em ombros no Teatro Villaret, comemorando assim o seu regresso à casa.

0 Teatro Villaret quase não chegava a parar: durante largos períodos tinha três sessões diárias e não raras eram as vezes em que este espaço era solicitado para iniciativas de outras entidades. Esta intensa actividade era sustentada por uma equipa de trabalho não muito numerosa mas coesa que, quando não se encontrava em funções, inventava pretextos para se juntar, chegando a formar o seu próprio Grupo Desportivo.

Autores e temática contemporâneos foram a escolha principal da programação teatral do Villaret. Desde o início, este teatro oferecia ao público repertórios diferentes por diferentes companhias. Pode dizer-se que havia uma tentativa de levar à cena um repertório para um público com referências culturais mais ambiciosas, ao mesmo tempo que a alta comédia, quase sempre protagonizada 

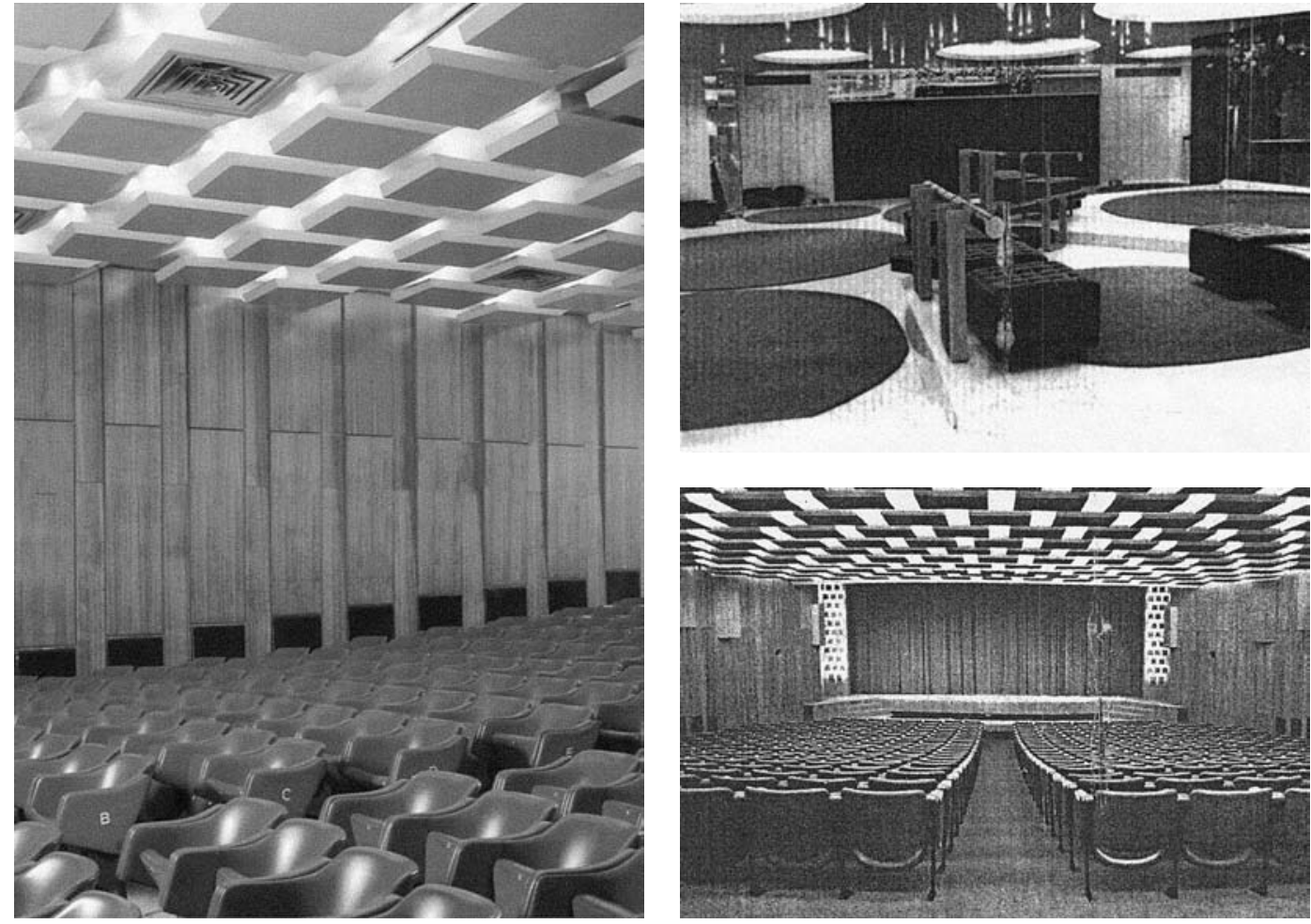

por Solnado, enchia a plateia e garantia que o novo teatro não fosse à falência. Assim, além da residente Companhia do Teatro Villaret, por lá residiu também, ainda que durante menos tempo, a Companhia Portuguesa de Comediantes - CPC, e por lá passaram, de forma mais ou menos prolongada, o TNT, a Companhia Teatro Alegre, a Companhia Brasileira do Teatro Isabel Princesa, o GAT, o Grupo 4, o TeJe... entre outros exemplos de teatro profissional nacional e estrangeiro. Mas também o teatro não profissional pôde contar com este palco para afirmar a sua existência e contactar com o seu público.

No Villaret foram apresentados recitais, como: O trovador maldito, com Juca Chaves; a poesia de Garcia Lorca, com Gabriela Ortega, ou Cancioneiro popular, com Joaquin Diaz. Por lá cantaram Vinícius de Morais, Nara Leão, Edu Lobo e Chico Buarque de Holanda (então exilado na Europa) e ia cantando Manolo Diaz, dos Aguaviva, se não fosse impedido pela PIDE. Fizeram-se espectáculos de dança, mesas-redondas e conferências, exposições e exibição de filmes. Assim, a uma intensa actividade teatral juntava-se uma variada oferta performativa. 0 Teatro Villaret ocupava nessa altura funções que hoje consideraríamos inerentes a um centro cultural.

E porque Raúl Solnado sabia da vontade de Ramiro Valadão, então na direcção da RTP, de experimentar novos programas, e porque as características físicas do Teatro Villaret o permitiam, Solnado, juntamente com Carlos Cruz e Fialho Gouveia, apresentaram uma proposta de criação de um novo programa televisivo: o Zip-Zip.

0 Zip-Zip foi a primeira experiência de estúdio aberto em televisão, o primeiro talk-show português. Ao longo de 32 programas o pais parava à segunda à noite e discutia semana fora o que se tinha passado no programa anterior. Conta-se que muitos teatros mudaram o dia de folga para segunda e os cinemas baixaram o preço dos bilhetes para esse dia por causa do Zip-Zip! À hora do Zip as ruas estavam desertas e... os cafés cheios? Só os que tinham televisão! Nunca um programa televisivo fora tão longe e despertara tanto interesse público. Contrariamente ao que hoje se passa, não se tratava de uma atitude amorfa, de um consumo passivo, mas antes de um questionar permanente, de um debater de ideias, de uma vontade de conhecimento que, de tanto esperar, parecia insaciável. Também aqui Solnado elevou o riso a uma arte. Muitos programa. Toda uma geração de baladeiros, que se celebraram após o 25 de Abril, passaram pelo Zip-Zip.

Como então escreveu Correia da Fonseca:

[0 Zip-Zip] veio contar-nos como alguns andam empenhados na construção de alguma coisa que se torne riqueza de todos. (...) Trouxe-nos uma juventude que empunha a viola para contar mágoas que não pertencem a um só, que são património de um povo inteiro. ${ }^{5}$

O Zip-Zip beneficiou certamente da "primavera marcelista" e, quando chegou ao fim, dixou um enorme vazio que só viria a ser preenchido, plenamente, na madrugada de 25 de Abril. Por isso, falar de Raúl Solnado e do Teatro Villaret é também falar na história da RTP e do País.

Com a criação do Teatro Villaret, Raúl Solnado não realizara apenas o sonho de construir um teatro, com tudo o que isso implicava. Realizava também a ambição de desenvolver a sua carreira de actor e de procurar que isso fosse reconhecido. Não esqueçamos que a sua imagem estava fortemente ligada à do humorista, das Histórias. É por isso pertinente perguntarmos se Solnado conseguiu ou não afirmar-se como actor, se conseguiu ou não fazer a evolução de humorista para comediante? De que forma a construção do seu próprio teatro se situou nessa tentativa de evolução?

Sobre a importância que teve o Teatro Villaret no seu percurso de actor escreveu João Medina: foram os ilustres e os desconhecidos que fizeram aquele
Sala de espectáculos do Teatro Villaret [Daciano da Costa Designer, Lisboa, Fundação Calouste Gulbenkian, 2001].

Foyer do Teatro Villaret [Arquitectura: Revista de arte e construção, n. 86 , Jan.-Fev. 1965].

Visão panorâmica da sala de espectáculos do Teatro Villaret [Arquitectura: Revista de arte e construção, n. 86, JanFev 1965]. 


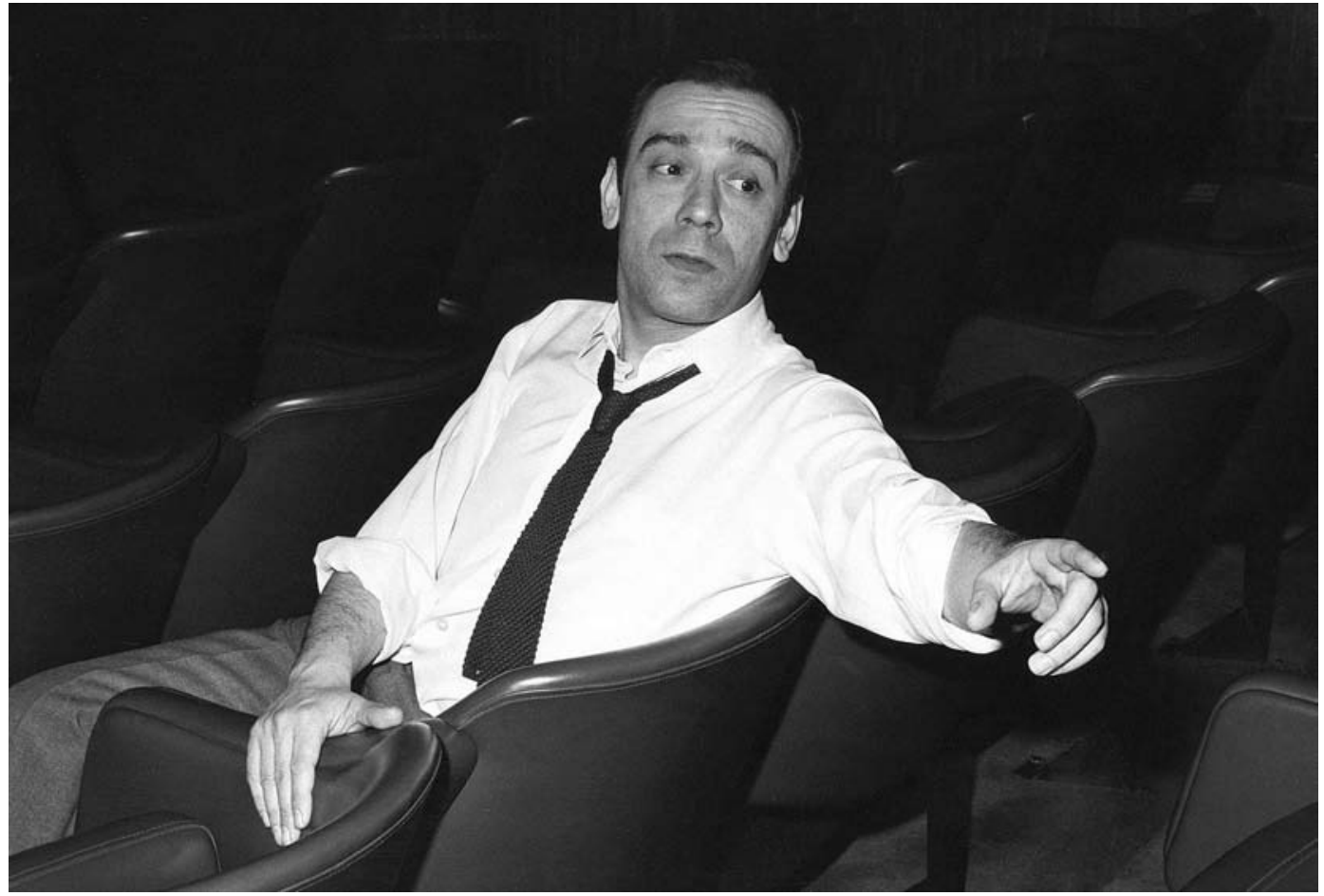

Tal como Ulisses, Solnado soube livrar-se também das sereias que o atraíam para os alçapões revisteiros do Parque Mayer. Tal parecia, efectivamente, o destino de Solnado: atolar-se no sub-teatro confeccionado à escala industrial para gáudio das plateias subdesenvolvidas. Livrando-se dessas sereias de pacotilha e rimel, Solnado prosseguiu viagem, Avenida acima, dobrou a Rotunda, singrou para Leste e tocou terra a meio da Avenida Fontes Pereira de Mello, ali fundando um simpático teatrinho de nome Villaret. Com esta viagem ganhou ele e ganhámos nós: o nosso teatro cómico ficou a contar com um estupendo actor, talvez mesmo o mais talentoso no género. Livrando-se do malfadado Parque, Solnado resgatou ainda alguns companheiros, tirando-os da mão de Circe, a deusa que transformava os homens em cevados. Ei-lo agora, no seu feudo, rodeado de bons actores, fazendo teatro e, sobretudo, fazendo rir sem recorrer aos processos estereotipados da banalidade revisteira. ${ }^{6}$

${ }^{6}$ Jornal do Fundão,

21/05/1967.

"O Tartufo: teatro comercial inteligente", in

Rádio \& Televisão,

05/02/1972.

${ }^{8}$ Na altura em Portugal, a convite do

Conservatório Nacional, como se refere no Diário de noticias, 09/02/1972.

${ }^{9}$ A capital, 26/01/1972.

${ }^{10}$ Entre elas Oliveira Salazar e o Cardeal

Cerejeira, como confirmou Solnado em registo áudio de $01 / 03 / 2004$.
É no Teatro Villaret, com a interpretação de Tartufo, de Molière, numa adaptação de Enrique Llovet (traduzida por Carlos Wallenstein) e encenação de Adolfo Marsillach, em 1972, que Solnado é unanimemente reconhecido pela crítica como um grande actor de comédia. A este propósito escreveu Fernando Midões:

Durante o diálogo que manteve connosco, Enrique Llovet, adaptador espanhol de Tartuffe, de Molière, confessou-nos que ficara um tanto perplexo ao saber das características de comediante de Raúl Solnado (previsto então como protagonista daquela obra) e que, durante o primeiro ensaio a que assistira, (...) não conseguira [eximir-se], em absoluto, a essa mesma perplexidade. Depois... sentira-se, pouco a pouco, vencido e convencido, resultando até ter descoberto, em Lisboa, mais uma face de Tartufo, um outro Tartufo possivel, um Tartufo irónico, alegre e de voz "burlona". (...) Solnado não "precisava" de tamanho risco. Solnado podia ficar muito "quietinho" a fazer peças homólogas do Vison voador. Solnado quis a aposta, o risco. (...) Mas alcançaria não ser Solnado-Solnado? Pois valeu a pena. E se esta crítica se inicia com uma chamada de atenção tão evidente para Raúl Solnado, não o faz por culto ao vedetismo, mas sim porque, muito realisticamente, ao não desprezar o facto concreto de Solnado, só por si, poder conduzir meia-Lisboa ao Villaret, procurará realce para outro facto: o de, naquela sala, não acontecer um espectáculo servindo uma vedeta, mas sim uma "vedeta" servindo um espectáculo.

0 Tartufo, que teve entre os seus espectadores Peter Brook ${ }^{8}$, terá sido um marco, não apenas na carreira de Raúl Solnado, mas nas produções do Teatro Villaret, no período a que me refiro. Manuela de Azevedo, Manuel Magro, Maria Helena Dá Mesquita, Luis d'Oliveira Nunes, Urbano Tavares Rodrigues, Carlos Porto, Amaro Spínola, Rui Pilar, Alice Ogando, Duarte Ivo Cruz, Gonçalves de Castro, João Assis Gomes, Joaquim Benite... são alguns dos nomes cuja crítica ao espectáculo e ao actor Raúl Solnado é francamente elogiosa, pela qualidade, sentido de inovação e interessante adaptação de um clássico. A este propósito diz Maria Helena Dá Mesquita:

0 importante é que o teatro nos mostre, como indica Marsillach, que esta obra clássica não está morta (...). Se o Tartufo for no palco apenas um paquiderme empalhado e empoeirado, ninguém terá vontade de o ver mas se, como ontem aconteceu no Villaret, for uma caricatura viva e actual, então será maravilhoso senti-lo próximo, apontá-lo com o dedo, poder dizer: "Tartufo é aquele". ${ }^{9}$

0 êxito da interpretação de Solnado, que em alguns momentos permitia analogias com figuras de destaque da sociedade portuguesa ${ }^{10}$, é pretexto para alguma intelectualidade, e não apenas os críticos, reflectirem sobre o trabalho dos actores portugueses. Assim Joaquim Benite, num longo artigo teórico sobre teatro rico e teatro pobre, faz algumas reflexões sobre o Tartufo, no Villaret, "a propósito de um espectáculo invulgar": 

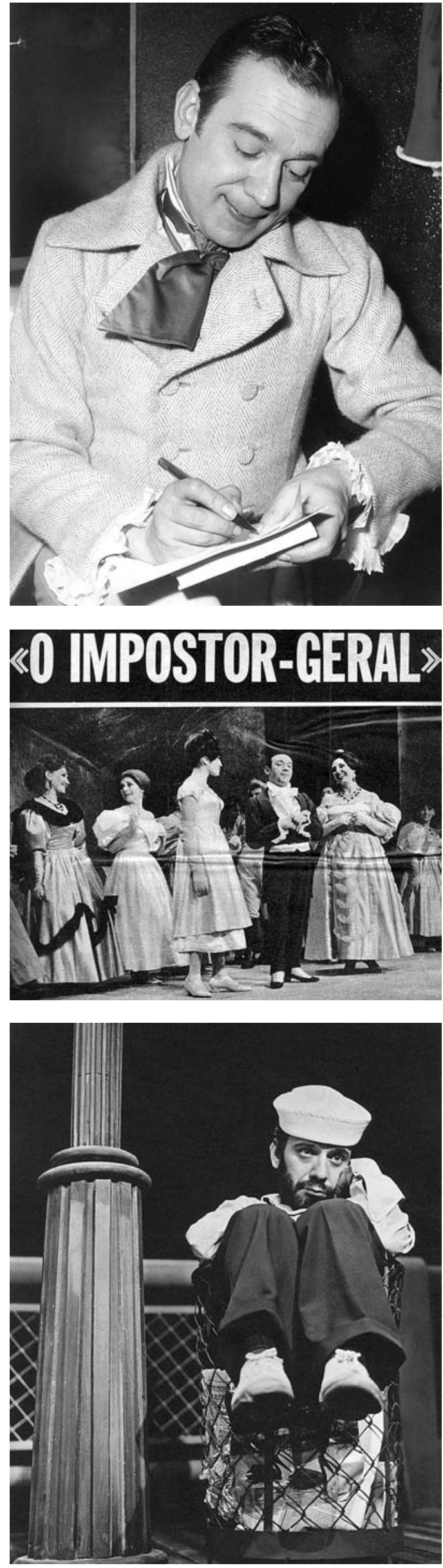

O impostor geral, de Gogol / Francisco Mata e Carlos Wallenstein, enc. Francisco Ribeiro, Teatro Villaret, 1965 (Raúl Solnado), fot. Lobo Pimentel.

0 ar formal que têm os nossos actores não é compativel com um exercício de gozo. Eles querem ter uma excelente dicção, uma excelente presença, sabem todas as maneiras de estar num palco, de se sentarem, de se levantarem. Saberão... Tentam baldadamente viver personagens, quando deviam mostrá-las, comentá-las, dá-las com um sentido crítico de que, pelo menos, não possuem a técnica da manifestação. Objectar-me-ão que Solnado é, fundamentalmente, uma personagem, e não um actor. E que talvez se passe o mesmo com Mauperrin. É verdade: mas a personagem que Solnado é já não é sua (de que, naturalmente, há muitos anos se despojou), mas uma outra, que ele criou no teatro, no jogo, na representação. E acontece que, pelo menos no Tartufo essa personagem encontra um aproveitamento perfeito."

Mas, se podemos dizer que Tartufo é o espectáculo que traz o reconhecimento consensual do actor Raúl Solnado e que este deu um contributo inestimável àquela personagem, outros aspectos da produção fizeram dele um espectáculo que merece destaque no estudo do teatro em Portugal. Refiro-me particularmente à filosofia da encenação. Com efeito, há nele uma nova atitude perante o espaço cénico, o cenário, os figurinos, a relação dos actores com todos estes elementos, bem como a relação palco-plateia, uma vez que é quebrada essa divisão clássica e a plateia igualmente utilizada como espaço cénico. Marsillach desvia-se da estética "decorativa" e da tendência de uma representação "à época" e faz uma leitura inovadora em Portugal. Como escreve Joaquim Benite a propósito do cenário:

Substitui o contra-regra, porque é de dentro dele que saem todos os apetrechos de cena (ou quase todos). Tem uma função satírica no espectáculo, porque também ele é uma caricatura de um palácio, não é um palácio. Está de acordo com a personagem principal, é o próprio Tartufo porque, tal como ele, possui várias faces e pode ser encarado de vários ângulos, todos falsos. É exterior e interior, grandioso e ridiculo,
O impostor geral,

de Gogol/ Francisco Mata e Carlos Wallenstein enc. Francisco Ribeiro, Teatro Villaret, 1965 [O século ilustrado 16 Jan. 1965].

Raúl Solnado em Amor às riscas, enc. Paulo Renato, Teatro Villaret, 1969 [arquivo pessoal de Raúl Solnado] de Murray Schisgall, 
de Molière / Enrique

Llovet

enc. Adolfo Marsillac,

Teatro Villaret, 1972

(Curado Ribeiro,

Fernanda Montemor

e Raúl Solnado)

[arquivo pessoal de Raúl

Solnado]

Urbano Tavares Rodrigues opinou: "Desta feita a publicidade não exagerou" (O século, 26/01/1972) e Carlos Porto é ainda mais ousado reconhecendo nesta encenação - como, de algum modo, Benite também acabaria por sugerir - a influência de Brecht:

(...) teatro visto como teatro: os actores vestem-se e despemse à frente do público (os fatos descem pela tela); dão indicações para a iluminação (...); usam fatos actuais com figurinos da época: Orgon coloca a cabeleira à vista do público; os próprios actores armam o palco (graças à amabilidade dos respectivos elementos e à engenhosidade do dispositivo cénico); há um constante contacto com o espectador. ${ }^{13}$

Embora a carreira de Solnado pudesse prosseguir fora do

enc. Adolfo Marsillac,

Teatro Villaret, 1972

(Raúl Solnado) fot. Eduardo Gageiro [0 século ilustrado

Jan.1972 Morgado, o Teatro Villaret continuava demasiado dependente da sua presença física, quer em palco, quer em decisões.

Só em 1971, com o espectáculo Vison voador, em cena desde o final de 1969, é que Solnado consegue libertarse da dívida à banca concluindo o pagamento do teatro na sua totalidade. Nesse dia juntou todos que o tinham ajudado na liquidação da dívida e realizou o jantar da "queima das letras" assinalando, simbolicamente, o final daquela caminhada.

Raúl Solnado continuará ligado ao Teatro Villaret até 1974. Nos últimos anos a gestão do teatro era feita alternadamente entre ele e Vasco Morgado, com quem, entretanto, se desentendera profissionalmente. As ausências de Solnado foram-se acentuando, e acentuou-se também o seu desejo de partir para novas aventuras na sua carreira artística. Era a sua vez de gerir o teatro quando se deu o 25 de Abril e Solnado decidiu produzir um espectáculo que o tinha impressionado, cerca de 10 anos antes, no Brasil: Liberdade, Liberdade!, de Millôr Fernandes e Flávio Rangel. Um telefonema para Luis de Lima bastou para que no final de Agosto aquele espectáculo estreasse.

Mas no final de 1974, Solnado vendeu a sua metade a Vasco Morgado. São várias as razões que podemos reconhecer para esta decisão: o último espectáculo que produzira não terá rentabilizado o investimento feito; uma situação de peculato, por parte de um secretário, deixara o Villaret economicamente fragilizado; a relação profissional com Vasco Morgado não atravessava o seu melhor
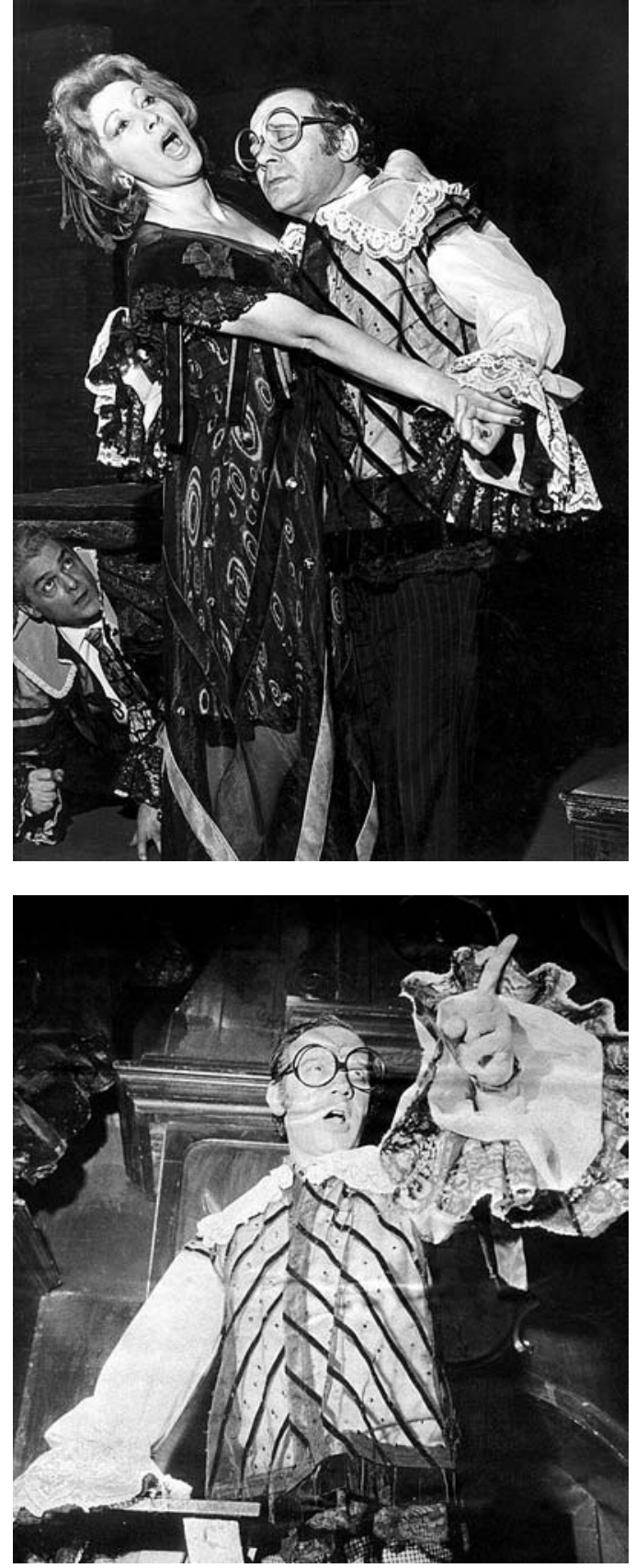

momento; o Teatro Villaret dava sinais de degradação fisica, o que obrigaria a um significativo investimento financeiro; por último, a instabilidade da situação política não seria a mais encorajadora para um proprietário e empresário de teatro.

Solnado entendeu que o seu projecto havia chegado ao fim e, com esse entendimento, não procurou encontrar alternativas que perpetuassem o seu poder naquele teatro. Ser actor foi o que sempre pretendeu, e a sua passagem pela edificação e gestão de um teatro foi o preço que pagou pelo actor que quis ser. Solnado quis deixar à sua cidade uma obra feita pelas suas próprias mãos, mas esse, apesar de concreto, é o lado menor da grandeza da obra que este actor nos legou. 0 outro mantém-se vivo na memória colectiva e ficará como referência na História do Teatro Português do Séc. XX, confirmando o título de uma notícia que, em tempos, anunciou a inauguração do Villaret: "Nunca tantos vão dever tanto a um só!"14 


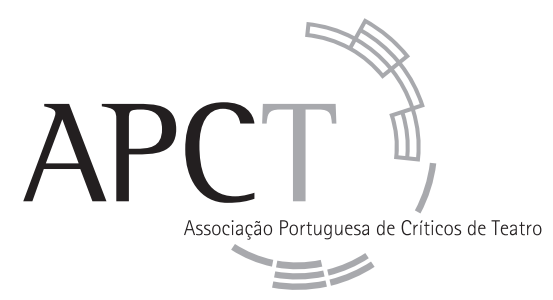

Presidente honorário $\quad$ Carlos Porto

\begin{tabular}{c|l} 
Direç̧ão & $\begin{array}{c}\text { Maria Helena Serôdio } \\
\text { Paulo Eduardo Carvalho } \\
\text { Rui Cintra }\end{array}$ \\
Consembleia Geral & $\begin{array}{l}\text { Luiz Francisco Rebello } \\
\text { Fernando Midões }\end{array}$ \\
ESTATUTOS Fiscal & $\begin{array}{l}\text { Ana Isabel Vasconcelos } \\
\text { Maria João Caetano } \\
\text { Mónica Guerreiro }\end{array}$ \\
$\begin{array}{l}\text { Capitulo Primeiro (Da Associação e dos seus fins) } \\
\text { Art. 2.0 }\end{array}$ & $\begin{array}{l}\text { A Associação tem por objectivo: } \\
\text { Dignificar, estruturar e responsabilizar a actividade crítica relativa à teoria e prática do teatro, } \\
\text { entendendo-se por actividade crítica não só a crítica de espectáculos, mas também tudo aquilo que } \\
\text { diga respeito à informação, reflexão e teorização no campo das artes performativas. }\end{array}$
\end{tabular}

\section{Colaboração com Sinais de cena}

A revista está aberta à participação de quem deseje colaborar enviando artigos que julgue corresponderem aos objectivos da publicação e às modalidades enunciadas pelas rubricas existentes. A consulta do sítio da APCT na Internet (www.apcteatro.org) e o contacto por correio electrónico (geral@apcteatro.org ou estudos.teatro@fl.ul.pt) são indispensáveis para conhecer as normas de apresentação dos artigos (dimensão, aspecto gráfico, citações, referências bibliográficas, ilustrações, etc.).

\section{ASSINATURA}

Desejo subscrever os números 6 e 7 da revista Sinais de cena (correspondentes a Dezembro de 2006 e Junho de 2007), no valor total de 22,00 a beneficiando assim de um desconto sobre o preço de venda ao público. Fora do pais: Europa 24,00 a / Fora da Europa 26,00 a.

Nome:

Morada:

\begin{tabular}{l|l} 
Código postal: & Pais:
\end{tabular}

Endereço electrónico:

\begin{tabular}{ll|l|} 
Forma de pagamento: $\square$ Vale postal $\quad \square$ Cheque $n^{\circ}$. & Banco \\
\hline
\end{tabular}

Preencha e envie este cupão (ou fotocópia do mesmo) para:

\section{Sinais de cena}

Centro de Estudos de Teatro

Faculdade de Letras de Lisboa: sala 67

Alameda da Universidade

1600-214 Lisboa (Portugal) 